\title{
In memoriam: Frederick Griffith Pearson, a legend in thoracic surgery and a great teacher (1926-2016)
}

\author{
Noriaki $\operatorname{Tsubota}^{1} \cdot$ Jean Deslauriers ${ }^{2}$
}

Published online: 10 December 2016

(C) The Japanese Association for Thoracic Surgery 2016

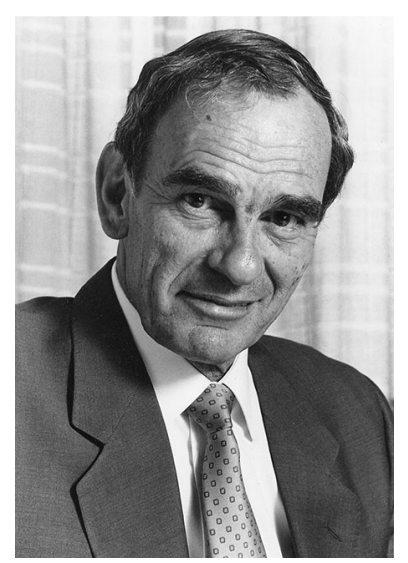

Surrounded by his close family, Doctor Frederick Griffith (Griff) Pearson passed away peacefully on August 10th 2016 at the age of 90 . He was an innovative surgeon, and without doubt, one of the most important architects of the spectacular growth that occurred in Thoracic Surgery after the end of World War II. His humility, energy, and warm character gained him respect throughout the thoracic academic world.

Born in Toronto in 1926, he was the eldest of three boys. In 1949, he completed his medical studies at the University of Toronto ( $\mathrm{U}$ of T) and in 1950, did one year of basic

Noriaki Tsubota

noritsu@hyo-med.ac.jp

Jean Deslauriers

jean.deslauriers@chg.ulaval.ca

1 Department of Thoracic Oncology, Hyogo College of Medicine, 1-1 Mukogawa, Nishinomiya City, Hyogo 663-8501, Japan

2 Laval University, 6364, Chemin Royal, Saint-Laurent-Iled'Orléans, Québec, QC G0A3ZA, Canada

research with Dr. Wilfred Bigelow, working on the applications of hypothermia in cardiac surgery. He subsequently went into general practice for three years in a small mining community in Northern Ontario, and according to him, this is where he became a "Good Doctor".

In 1955, he began his surgical residency at Toronto General Hospital (TGH) and developed a marked interest in Thoracic Surgery. In 1959, he was the recipient of the prestigious "McLaughlin Travelling Fellowship" award and embarked for Europe to study with the "Master Thoracic Surgeons" of that era. He first spent time with the late Ronald Belsey (Bristol, UK) where he learned the basics of academic surgery and how to hold his scissors "upside down" while operating! He was profoundly influenced by Belsey's systematic approach to problem solving and by his obsession with details. He then traveled to Scandinavia where he met had Eric Carlens (Stockholm), a bronchologist who had first described the operation of mediastinoscopy which he was doing to document the amount of silicosis in the lymph nodes of underground miners. The following is what Griff recalled about his learning of mediastinoscopy with Carlens:

"He had me stick my middle finger through the incision into the mediastinum, and I was sold on the ingenuity of this approach for simultaneous bilateral exploration of the nodes in the superior mediastinum".

Upon his return to Toronto in the early $60 \mathrm{~s}$, he was the first to promote the routine use of mediastinoscopy during the preoperative evaluation of presumed operable patients with lung cancer [1]. His overall work on the surgical treatment of lung cancer finally led to the creation of the Lung Cancer Study Group (LCSG), a US-based research 
group that has established the gold standards of excellence for clinical trials in thoracic surgical oncology.

In 1967, he put together the first "stand-alone" Division of Thoracic Surgery (being separate from cardiac and general surgery) in Canada and likely in the world. This model not only led the Royal College of Physicians and Surgeons of Canada to recognize Thoracic Surgery as a "Primary Specialty", but the model also replicated throughout the world, especially in Europe. His leadership in shaping up the identity of Thoracic Surgery, both in Canada and internationally cannot be underestimated. As a result, several people refer to him as the "Godfather" of modern Thoracic Surgery. During those early years, he also conceptualized the "Toronto School of Thought" whose elements he was able to teach to the hundreds of surgeons visited him, and who subsequently became specialty leaders in their own countries. He was an inspiration and a role model to everyone, including the younger generation.

The following are personal quotes both from the authors of this article as well as from others that we received following Dr. Pearson's death:

I first met Dr. Pearson in 1973 at TGH and I owe it totally to him that I became a thoracic surgeon. Without the time spent with him, I could not have introduced various techniques and ideas in Japan. More than that, what I have learned from Griff was modesty, friendliness, and kindness toward young fellows. Even after I left Toronto, he kept encouraging me (Noriaki Tsubota, Nishinomiya City, Japan, Fellow in Toronto, 1973-74).

"Dr. Pearson is the only great academic surgeon that I have met in more than 45 years. He enjoyed watching the progress of his pupils and helped them become better that he was. This is the great recipe of the Toronto Thoracic Surgery Group which Griff created in the early days". (Sandro Mattioli, Bologna, Italy, Fellow in Toronto, 1988-89)

"Of course, there were other important thoracic surgeons over the years, but none had Griff's combination of humility, skills, scholarship, enthusiasm, and charisma." (G Alexander Patterson, Saint-Louis, Missouri, USA, former colleague of Griff Pearson in Toronto)

“A mere summary of Dr. Pearson's academic and administrative accomplishments does not provide a full picture of the man he was. His daring foresight and practical sense, combined with imagination and technical ability, clearly make him an innovator and icon in the specialty of Thoracic Surgery." (Jean Deslauriers, Quebec City, Canada, Resident in the
Toronto Thoracic Surgery training program, 1969-75)

Griff was a passionate researcher and scientist yet perhaps his greatest contribution was the influence that he had on young talented researchers from all continents over a period of more than half a century.

In the early 1970s, Dr. Pearson and his research group were the first to demonstrate that benign tracheal strictures were due to the use of endotracheal and tracheostomy tubes with high pressure cuffs [2]. A few years later, he became widely recognized, together with his contemporary, Dr. Hermes Grillo from Boston, as the "Leader" in the development of airway surgery, introducing new techniques to treat the most complex of problems. In 1975, he described an operation for the resection of subglottic strictures with preservation of the recurrent nerves, a procedure still called the "Pearson Operation" [3]. During one such operation, Dr. Pearson said to one of the author of this article (NT) at a critical time of the operation, "Don't move your hand, Nori, leave the pulling stitches as they are".

Dr. Pearson's expertise in airway surgery became pivotal in the development of techniques pertinent to successful human lung transplantation. He was also an important contributor to the establishment of an experimental research laboratory, a lab that became the site of groundbreaking pioneering work in the field. Under his leadership and that of Drs. Cooper, Patterson, and Todd (Fellow resident with Noriaki Tsubota in 1973) the Toronto Transplant Group performed the world's first successful single human lung transplant (Cooper et al. 1983) as well as the first successful human double-lung transplant (Patterson et al. 1986). These historical milestones reflect the incredible "Team Spirit" of the Toronto group, a spirit initially inspired by Griff Pearson. Since those early days, many Japanese thoracic surgeons have visited Toronto, and had they not acquired this specialized knowledge, the success of Japanese lung transplantation programs would never have been able to materialize.

In the field of esophageal surgery, his interests were focused on the management of benign esophageal diseases, interests that he had developed during the time spent with Ronald Belsey. He performed hundreds of Belsey Mark IV anti-reflux procedures always handling the instruments in the typical Belsey "upside down" manner. Regularly confronted with the problem of reflux-related short esophagus, he introduced the Collis-Belsey procedure also called the "Pearson Procedure" which combined a Collis lengthening gastroplasty with a Pearson modification of the Belsey's Mark IV [4]. For many years, this procedure was the gold standard for the surgical management of short esophagus. 
He was a brilliant, inspiring, and charismatic teacher whose commitment to trainees was legendary. He possessed critical and analytic thinking skills as well as the remarkable talent to transmit clearly his thoughts. He was generous of his time and always willing to spent huge amounts of it with residents, fellows, and visitors alike. He made an effort to make sure that everyone felt at home in Toronto. He was the inspiration behind the publication of the first three editions of the specialty textbooks entitled "Pearson Thoracic Surgery" and "Pearson Esophageal Surgery". Both of these textbooks became bestsellers and have been consulted by countless numbers of thoracic surgeons the world over, including those in Japan.

Dr. Pearson was President of the American Association of Thoracic Surgery (AATS) in 1989-90 and received the first Lifetime Achievement Award from that Association in 2004. For his contributions, he was "Honorary Member" of several international associations including the Japanese Association for Cardio Thoracic Surgery. He was also the member of the "Order of Canada", the highest civilian distinction in Canada.

Over the years, Dr. Pearson was the guest speaker at several Japanese specialty meetings including that of the Japanese Association for Thoracic Surgery. His visit to Hiroshima in 2010 at the age of 84 was his last journey to Japan. After the official meeting was over, he kindly took part in a series of unofficial workshops called "Lets talk with Dr. Pearson" which held in Osaka and Tokyo. Surrounded by many young Japanese thoracic surgeons during two evenings, he discussed among other topics, the role of bronchoplasties and limited resections in the surgical management of lung cancer. Upon his return to Toronto, he sends me (Nori) the following note: "Those two evenings were amongst the most wonderful I ever had in Japan".

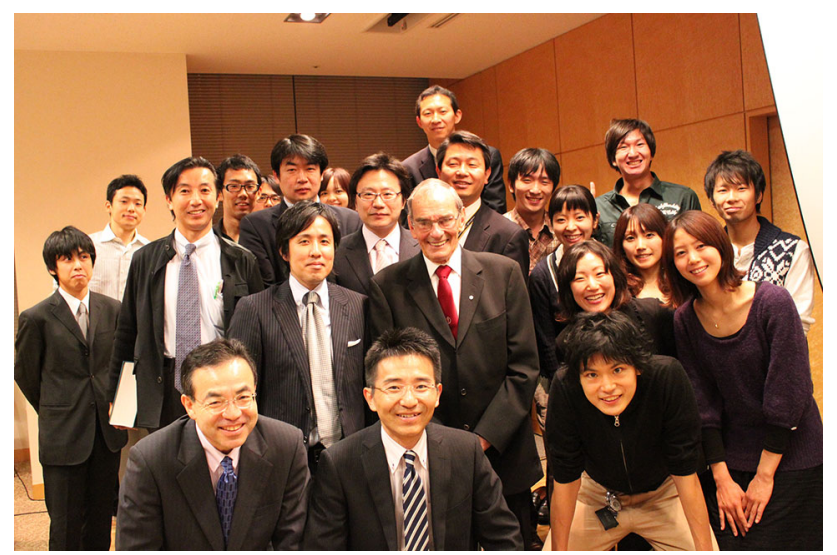

Dr. Frederick Griffith Pearson was a great thoracic surgeon, an innovator, and an extraordinary talented teacher. He had a profound influence on several of his trainees both on their professional and personal lives. He redefined the specialty of Thoracic Surgery and regarded by his colleagues as the founder of contemporary Thoracic Surgery. His talent, creativity, integrity, charisma, and dynamic personality were an inspiration to those of us fortunate to have been his students. He is the embodiment of a "True Legend" in Thoracic Surgery.

Note from the Editor: In 2015, Griff Pearson along with Jean Deslauriers, co-author of this article, and Bill Nelems, edited a textbook entitled "Evolution of Thoracic Surgery in Canada". This textbook details the numerous accomplishments of Canadian thoracic surgeons, most notably those of Griff Pearson and interactions between doctors coming from all over the world to Toronto, over the past 100 years. Most importantly, all proceeds from book sales donated to a Pearson foundation, whose main objective is to support research in Canadian thoracic surgery. The book can be availed through the Canadian Association of Thoracic Surgeons website at http://www.canadianthor acicsurgeons.ca/evolution-of-thoracic-surgery-in-canada/.

\section{References}

1. Pearson FG. Mediastinoscopy: a method of biopsy in the superior mediastinum. J Thorac Cardiovasc Surg. 1965;49:11-21.

2. Pearson FG, Goldberg M, Da Silva AJ. Tracheal stenosis complicating tracheostomy with cuffed tubes. Clinical experience and observation from a prospective study. Arch Surg. 1968;97:380-94.

3. Pearson FG, Cooper JD, Nelems JM, Van Nostrand AW. Primary anastomosis after resection of the cricoid cartilage with preservation of recurrent laryngeal nerves. J Thorac Cardiovasc Surg. 1975;70:806-16.

4. Pearson FG, Cooper JD, Patterson GA, et al. Gastroplasty and fundoplication for complex reflux problems. Long-term results. Ann Surg. 1987;206:473-81. 